\title{
Deliberate self-harm in adolescents in Southern Sri Lanka; a hospital based study
}

\author{
Senadheera $\mathbf{C}^{1}$, Marecek $\mathbf{J}^{2}$ \\ ${ }^{\prime}$ Department of Psychiatry, Faculty of Medicine, University of Ruhuna, Sri Lanka. \\ ${ }^{2}$ Department of Psychology, Swarthmore College, USA.
}

Correspondence: Dr. Chandanie Senadheera

e-mail: chandaniesenadheera@yahoo.co.uk

iD https://orcid.org/0000-0003-3772-1365

\begin{abstract}
Introduction: Little is known about adolescents who engage in deliberate self-harm (DSH). Therefore, using data from medical and police records of the Teaching Hospital Karapitiya, we examined patterns of DSH among young people.
\end{abstract}

Methods: We examined records of episodes of DSH for 2001 and for the 5 year period from 2006 through 2010. Data on 1720 individuals between 10 and 18 years old were gathered.

Results: There was a striking increase from 2001 to 2010 in admissions of young people with DSH. In 2001, there were 137 cases; in 2010, the number had nearly tripled ( $\mathrm{N}=391)$. Case fatality rates were low; in 2001, it was $8 \%$; in 2010 , it was $0.25 \%$. Comparing 2001 to 2010 , cases involving poisons decreased from $58 \%$ to $46 \%$; cases involving medicinal overdoses increased from $41 \%$ to $54 \%$. Adolescents rarely used other methods. In 2001 and in each year from 2006 to 2010, adolescents aged $15-18$ years accounted for at least $85 \%$ of the sample, and there were three times more girls than boys.

Conclusion: Decreases in suicides have been substantial; nonetheless, rates of non-fatal DSH have climbed. We call for research on antecedents and correlates of DSH in groups at high risk, such as older adolescent girls.

Keywords: Adolescents, case fatality rate, deliberate self-harm, gender differences, paracetamol

\section{Introduction}

Suicide has been a matter of concern in Sri Lanka since an upward spiral of deaths was reported in the early 1970s (1). By 1995, the number of deaths peaked at $47 / 100,000$, one of the highest rates of suicide in the world (2). From the late 1990s, the suicide rate declined; the latest figures report an annual incidence of 17/100,000 (3). Adolescents and young adults - particularly females - account for a disproportionate number of suicide deaths. In every year from 1976 to 2011, women between the ages of 17 and 25 had higher rates of self-inflicted death than women in any other age group (4).
The decrease in suicides since late 1990s has been attributed largely to restrictions on agricultural pesticides $(2,5)$. This decline in deaths is certainly welcome. However, evidence of hospital admissions, as well as household survey data, reveals that the incidence of nonfatal deliberate self-harm is very high and has been consistently increasing. Recently, a large-scale household survey in the North Central province conducted between 2010 and 2013 recorded a rate of nonfatal self-harm of roughly 560/100,000 among individuals aged 14 years and older (6). A broad consensus has emerged in the research in Sri Lanka that suicide and nonfatal 
deliberate self-harm typically occur in a context of acute interpersonal conflict (7-11). Suicidal acts can be prompted by a variety of motives other than a wish to die. The high rates of hospital admissions for nonfatal deliberate self-harm, regardless of whether or not such acts reflect a wish to die, place a strain on medical resources, as well as on communities and families.

In the present study, we focus particularly on adolescents who have engaged in deliberate selfharm, drawing on information available in their medical records.

\section{Methods}

We conducted a retrospective survey of medical records at Teaching Hospital, Karapitiya (THK). The THK is the only tertiary-care government hospital in the South of the country, and it serves as the referral centre for the entire Southern province. Most cases of self-inflicted harm (especially selfpoisoning) are treated in government hospitals. Therefore, we assumed that admissions to the THK constituted a reasonably representative group of DSH patients.

In accord with the World Health Organization guidelines (12), we considered individuals between 10 and 19 years of age to be adolescents, and so we selected the hospital records of all patients admitted for DSH who were between 10 and 18 years old.

In addition to accessing hospital records, we consulted the registry of the hospital's Police Post. This enabled us to gather data on individuals who died en route to the hospital, and to corroborate deaths that had occurred in hospital.

Four medical pre-interns were trained to extract data from Bed Head Tickets (BHTs). BHTs were gathered for 2001 and for every year between 2006 and 2010. Overall, data pertaining to 1720 individuals were recorded. There were no instances of repeated DSH. Cases of accidental self-harm were excluded. In a few cases, it was unclear whether the self-harm was deliberate or accidental; in these cases, the full BHT was reviewed by the investigator and the research team. If a consensus did not emerge, the case was excluded.

We extracted the following information from the records: demographic data, detailed information about the method(s) of harm the individual used; the date of admission and the length of hospitalization; whether the self-harm was fatal or not; and other relevant details or comments noted in the record. If information was missing from the BHT, we consulted other sources (such as record room registers) in an effort to complete the data.

Approval for the study was obtained from the Ethical Review Committee of the Faculty of Medicine, University of Ruhuna.

\section{Results}

Over the 10-year period between 2001 to 2010, the number of adolescents admitted to hospital for DSH nearly tripled. As table 1 shows, the number of admissions increased by $286 \%$.

The gender and age composition of the 2001 and 2010 cohorts was examined. In both 2001 and 2010, older adolescents (those aged 15-18 years) accounted for at least $87 \%$ of the admissions. Moreover, in 2001 and in 2010 three times more girls than boys were admitted to hospital (table 1).

Yearly data from 2006 to 2010 provide a more finegrained picture of adolescents' self-harm. Overall, there were consistent increases over this 5 year period in the number of adolescents admitted to hospital for DSH, with a $53 \%$ increase overall. As table 2 shows, girls accounted for roughly threequarter of the admissions in every year. The proportion of older adolescents (those aged15- 18 years) varied between $86 \%-93 \%$ of the admissions over the 5 year period.

The records also provided information about the method(s) the adolescents used for self-harm. Nearly all (99\%) had ingested one or more harmful substances. These substances included household chemicals (e.g. bleach, kerosene oil, and mosquito coils); poisonous plants (niyangala; yellow oleander seeds); agrochemicals (pesticides and weedicides); and overdoses of various medications. A comparison of 2001 and 2010 shows that, generally speaking, there seemed to be little change in adolescents' reliance on ingesting harmful substances, rather than using such methods as self-immolation or hanging. In 2001, $95 \%$ of the adolescents $(n=130)$ had ingested harmful substances; in 2010, $99 \%$ had done so $(n=388)$. 
There were two notable differences between 2001 and 2010. First, there was a considerable increase in medicinal overdoses; mainly due to the increase in paracetamol overdoses. The use of paracetamol had doubled. In 2001, 21\% of adolescents $(n=29)$ had ingested paracetamol overdoses; in 2010, $42 \%$ $(n=167)$ had. The use of other medicines decreased. None of the paracetamol overdoses was fatal (table 3 ). The second notable change from 2001 to 2010 was the decline in adolescents' use of agrochemicals, including the highly toxic weedicide Paraquat. In 2001, 21\% of the adolescents had ingested an agrochemical. In 2010 , only $8 \%$ had.

Now we turn to the 5-year period from 2006 to 2010. As table 4 shows, throughout this period, medicinal overdoses were the most common method of DSH. Admissions for agrochemical poisons declined by half over the 5 year period; however, admissions for other types of poisons (such as house-hold substances and poisonous plants) increased substantially.

By 2010, paracetamol had become the most common method that adolescents used for DSH. The number of tablets they reported having swallowed ranged from 5 to 120 , though these reports likely are not wholly accurate. For the period of 2006-2010, paracetamol overdoses constituted $48 \%(n=754)$ of total admissions. Thirty nine percent $(\mathrm{n}=146)$ of boys and $50 \%(n=608)$ of girls had taken paracetamol overdoses.

Table 1: Cases of DSH among adolescents: 2001 and 2010

\begin{tabular}{lll}
\hline Year & $\mathbf{2 0 0 1}$ & $\mathbf{2 0 1 0}$ \\
\hline Boys & $\mathbf{3 7}(\mathbf{2 7 \%})$ & $\mathbf{1 0 1}(\mathbf{2 6 \%})$ \\
$10-14$ years & 4 & 13 \\
$15-18$ years & 33 & 88 \\
\hline Girls & $\mathbf{1 0 0 ( 7 3 \% )}$ & $\mathbf{2 9 0}(\mathbf{7 4 \%})$ \\
$10-14$ years & 13 & 35 \\
$15-18$ years & 87 & 255 \\
Total & $\mathbf{1 3 7}$ & $\mathbf{3 9 1}$ \\
\hline
\end{tabular}

Table 2: Cases of DSH among adolescents: 2006 - 2010

\begin{tabular}{llllll}
\hline Year & $\begin{array}{l}\text { Young boys } \\
\text { (age 10-14) }\end{array}$ & $\begin{array}{l}\text { Young girls } \\
\text { (age 10-14) }\end{array}$ & $\begin{array}{l}\text { Old er boys } \\
\text { (age 15-1 8) }\end{array}$ & $\begin{array}{l}\text { Older girls } \\
\text { (age 15-18) }\end{array}$ & Total \\
\hline 2006 & $7(3 \%)$ & $28(11 \%)$ & $51(20 \%)$ & $169(66 \%)$ & $\mathbf{2 5 5}$ \\
2007 & $4(2 \%)$ & $18(7 \%)$ & $57(22 \%)$ & $183(70 \%)$ & $\mathbf{2 6 2}$ \\
2008 & $15(5 \%)$ & $27(9 \%)$ & $49(15 \%)$ & $229(71 \%)$ & $\mathbf{3 2 0}$ \\
2009 & $13(4 \%)$ & $22(6 \%)$ & $79(22 \%)$ & $241(68 \%)$ & $\mathbf{3 5 5}$ \\
2010 & $13(3 \%)$ & $35(8 \%)$ & $88(21 \%)$ & $255(68 \%)$ & $\mathbf{3 9 1}$ \\
\hline
\end{tabular}


Table 3: Methods used by adolescents for self-harm, 2001\& 2010

\begin{tabular}{lll}
\hline Method & $\mathbf{2 0 0 1}$ & $\mathbf{2 0 1 0}$ \\
\hline Medicine overdoses & $\mathbf{3 9 \%}(\mathbf{5 5 )}$ & $\mathbf{5 4 \% ( 2 1 1 )}$ \\
[Paracetamol] & $21 \%(29)$ & $42 \%(167)]$ \\
Poisons (incl. plants) & $\mathbf{3 5 \%}(\mathbf{5 0 )}$ & $\mathbf{3 8 \% ( 1 5 0 )}$ \\
Agrochemicals & $\mathbf{2 1 \% ( 2 9 )}$ & $\mathbf{8 \%}(\mathbf{3 0})$ \\
[Paraquat] & $4 \%(6)$ & $1 \%(5)]$ \\
Other methods & $\mathbf{5 \%}(\mathbf{7})$ & $\mathbf{1 \% ( 3 )}$ \\
\hline
\end{tabular}

(Percentages add up to slightly more than 100 because some participants used more than one method).

Table 4: Methods used by adolescents for self-harm, 2006 to 2010

\begin{tabular}{lllll}
\hline Year & Overdoses & Poisons & Agrochemicals & Other \\
\hline 2006 & $65 \%(164)$ & $19 \%(49)$ & $16 \%(42)$ & 2 \\
2007 & $63 \%(166)$ & $25 \%(66)$ & $14 \%(36)$ & 1 \\
2008 & $65 \%(205)$ & $24 \%(76)$ & $12 \%(37)$ & 2 \\
2009 & $63 \%(222)$ & $28 \%(99)$ & $9 \%(31)$ & 3 \\
2010 & $54 \%(211)$ & $38 \%(150)$ & $8 \%(30)$ & 3 \\
\hline
\end{tabular}

(Percentages add up to slightly more than 100 because some participants used more than one method).

Overall, very few adolescents succumbed to death; the rate of fatalities was roughly $2 \%(n=33)$. Moreover, the absolute number of fatalities, as well as case fatality rates (CFR, that is, the proportion of cases that ended in death) declined considerably over time. In 2001, there were 137 admissions and 11 deaths. Older adolescents accounted for all but one of the deaths. In 2010, there were 391 cases and only one death. The CFR decreased dramatically over the 10 -year period, from $8 \%$ to $0.025 \%$. During the 5 year period from 2006 to 2010 , the CFR overall was only $1.4 \%$. Older adolescents accounted for most $(86 \%)$ of these deaths.

The sharp decline in the death rate over time merits scrutiny. One likely cause of this decline is the shift to less lethal means. In 2001, 36\% of the deaths among adolescents resulted from paraquat ingestion.
In 2010 , there were no deaths due to paraquat. In $2001,4 \%$ of the adolescents took paraquat, in 2010, only $1 \%$ took paraquat. In the intervening years, restrictions had been placed on the import and sale of paraquat (2).

\section{Discussion}

Because this study relied on medical records, the data may not be wholly accurate. Medical staff may make errors in recording; patients may sometimes be less than truthful about what they ingested. Nonetheless, it is unlikely that the dramatic patterns of change that we observed are in error. One such pattern is that over the 10 year period of the study, adolescents' hospital admissions for DSH nearly tripled. The increase was similar for younger and 
older adolescents and for boys and girls. A second notable finding is the consistent preponderance of girls among adolescent DSH cases.

The data also revealed a sharp shift over time toward admissions for paracetamol overdoses, a shift that has been noted by other researchers as well (13). Although paracetamol overdoes are rarely fatal, this shift has practical import. Such overdoses may require costly medical intervention(14).

Limiting the availability of paraquat had a dramatic salutary effect on rates of self-inflicted death. However, the strategy of limiting availability has only a limited utility. Many of the substances that adolescents ingested are in everyday use in many households-bleach, toilet cleaner, mosquito coils, kerosene oil, and prescription medicines. Paracetamol-mainly in the form of Panadol tablets is freely available, inexpensive, and consumed routinely by many people. Many households and school classrooms keep a substantial supply on hand. Furthermore, youngsters can easily purchase packets of tablets at local shops without being questioned. Our view is that efforts to prevent suicide/DSH must also address the circumstances and motives that give rise to self-harm $(9,11,15)$.

The findings point to substantial differences between adolescents' and adults' self- inflicted harm. For example, adolescents have a much lower CFR than adults. When considering adolescents, public health personnel, researchers, and prevention practitioners need to refrain from drawing inferences about nonfatal DSH on the basis of fatalities. Among adolescents, the latter represent only a miniscule subset of cases of self-inflicted harm, and that subset may be highly unrepresentative.

The findings also point to a radical difference between adolescents and adults in the gender distribution of both suicide and nonfatal DSH. This difference ought to alert researchers to the necessity of narrowing their investigations to specific age groups and gender groups. Generalizations made on the basis of aggregate data likely will cover over important information about the social ecology, environmental stressors, and social aftermath of DSH.

Compared to deaths, nonfatal DSH has far less often been a focus of attention. Given its rising incidence, however, it seems unwise to ignore it.
Medically speaking, nonfatal DSH may not be trivial; in some cases, it can lead to long-term physical injury, such as liver damage and esophageal scarring. In addition, the medical resources - both human and material-required for some cases can strain the under-resourced health care system.

\section{Acknowledgments}

We thank L.M.P. Jayasiri, S.R. Jayawardena, K.L.A. Udenika, and S.D. Jinendrarathna, who were recent medical graduates at the time this study was carried out, for their assistance in gathering the medical record data.

The study was funded by American Institute of Sri Lankan Studies.

[Authors wish to mention that initial data for 2001, $2006 \& 2007$ were published as a research letter in Ceylon Medical Journal (C Senadheera, J Marecek, C Hewage and W A A Wijayasiri. A hospital-based study on trends in deliberate selfharm in children and adolescents. Ceylon Medical Journal 2010: 55(2):67-68)].

\section{References}

1. Kearney RN, Miller BD. The spiral of suicide and social change in Sri Lanka. The Journal of Asian Studies, 1985;45: 81-101.

2. Gunnell D, Fernando R, Hewagama M, et al. The impact of pesticide regulations on suicide in Sri Lanka. International Journal of Epidemiology, 2007;36: 1235-42.

3. Knipe DW, Gunnell D, Eddlestone E. Preventing deaths from pesticide self-poisoning-learning from Sri Lanka's success. The Lancet, 2017; 5: e651-52. [Available at: www.the lancet.com/ lancet vol. 5 July 2017].

4. Knipe DW, Metcalfe C, Fernando R, et al. Suicide in Sri Lanka 1975-2012: age, period and cohort analysis of police and hospital data. BMC Public Health, 2014; 14: 839-50.

5. Knipe DW, Chang SS, Dawson A, et al. Suicide prevention through means. restriction: impact of the 2008-2011 pesticide restrictions on suicide in Sri Lanka. PLoS One, 2017; 12: e017289. 
6. Pearson M, Metcalfe C, Jayamanne S, et al. Effectiveness of household lockable pesticide storage to reduce pesticide self-poisoning in rural Asia: A community-based, cluster-randomised controlled trial. The Lancet, August 2017;390: 1863-72.

7. de Silva HJ, Katuriarachchi N, Seneviratne SL, et al. Suicides in Sri Lanka: points to ponder. Ceylon Medical Journal, 2000: 45(1):17-24.

8. Jayasinghe NRM, Foster JH. Deliberate self-harm / poisoning, suicide trends: The link to increased alcohol consumption in Sri Lanka. Archives of Suicide Research, 2011; 15(3): 223-37.

9. Marecek J, Senadheera C. 'I drank it to put an end to me':Narrating girls' suicide and self-harm in Sri Lanka. Contributions to Indian Sociology, 2012; 46: 53-82.

10. Rajapakse T, Griffiths KM, Christensen H, Cotton S. Nonfatal self-poisoning in Sri Lanka: Associated triggers and motivations. BMC Public Health, 2015; 15: 1167-74.

11. Widger, T. Suicide in Sri Lanka: The anthropology of an epidemic. Rout ledge 2015.
12. WHO, n.d., Definitions and indicators in family planning, maternal and child health and reproductive health used in WHO/EURO. [online] Available at: http;//www.euro. who.int/document/e68459.pdf [Accessed 22 September 2018].

13. Senaratne SMDKG, Sri Ranganathan S, Dawson, AH, et al. Management of acute paracetamol poisoning in a tertiary care hospital. Ceylon Medical Journal 2008; 53: $89-92.1$

14. De Silva, V, Rathnayake A, Cost of the paracetamol overdose epidemic. Ceylon Medical Journal, 2010; 55:33.

15. Sørensen JB, Sørensen BR, Konradsen F, Rheinländer, T. 'We lost because of his drunkenness': The social processes linking alcohol use to self-harm in the context of daily life stress in marriages and intimate relationships in rural Sri Lanka. BMJ Global Health, 2017; 2(4): e000462. [Published online 2017 Dec 5]. 